\title{
AVALIAÇÃO DO FÍGADO DE CÃES NECROPSIADOS NO HOSPITAL VETERINÁRIO DA UNOESTE
}

Osimar de Carvalho Sanches, Rogério Giuffrida, Poliana Cavaleti, Rafaela Vitória Marchini Souza, Vanessa Cristina Pereira

Medicina Veterinária- Universidade do Oeste Paulista - UNOESTE. E-mail: osimar@unoeste.br

\section{RESUMO}

O fígado é considerado uma glândula, pois realiza várias funções metabólicas, e representa entre 2 a $5 \%$ do peso corpóreo do animal, é dividido em lobos e revestido por uma capsula fibrosa de tecido conjuntivo. Tem como unidade morfológica o lóbulo hepático. As lesões que acometem o fígado podem ser de origem degenerativa, inflamatória (tóxica e infecciosa) e neoplásica. As hepatites com origem infecciosa têm como agentes as bactérias, protozoários e os vírus. Quanto ao padrão inflamatório às hepatites podem ser aguda ou crônica, e na fase terminal é denominada de cirrose. Já a neoplasia mais comum é o carcinoma hepatocelular, entretanto, o órgão pode ser acometido por neoplasias metastáticas. Os dados foram colhidos de todos os animais necropsiados no serviço de anatomia patológica animal, do Hospital Veterinário da Universidade do Oeste Paulista- UNOESTE, município de Presidente Prudente, São Paulo. O objetivo do presente estudo é avaliar dados epidemiológicos quanto a idade, raça, peso do animal e peso do fígado dos cães necropsiados. O trabalho faz parte de um projeto registrado na CEUA com o № 1188 .

Palavras-chave: Fígado, alterações patológicas, inflamatória, infecciosa, neoplásica.

\section{INTRODUÇÃO}

O fígado pesa em média $450 \mathrm{~g}$, o que corresponde de 2 a $5 \%$ do peso corpóreo, sendo ele relativamente grande. É revestido por peritônio e localiza-se na parte mais cranial do abdômen, imediatamente atrás do diafragma (Banks, 1992; Dyce et al, 1990).

O órgão é uma glândula com numerosas funções metabólicas, executadas por dois tipos celulares: o hepatócito que faz síntese, secreção, excreção, armazenamento, biotransformação e metabolismo, possui também núcleo centralizado, e ainda podem ser binucleados, com várias mitocôndrias; e a célula de Kupffer, um macrófago, que é localizado na parede dos sinusóides hepáticos, associado ao hepatócito, onde executa função fagocitária (Banks, 1992).

A unidade morfológica do fígado é o Lóbulo Hepático, que são estruturas poligonais de tecido, formadas por placas de hepatócitos interligadas entre os sinusóides anastomosados, que se irradiam a partir do vaso posicionado ao centro, a veia centrolobular. Já o sangue dos vasos interlobulares é transportado pelos sinusóides em direção às veias centrolobulares. São os sinusóides que separam os cordões de hepatócitos uns dos outros, onde ocorre movimento de materiais entre o plasma e os hepatócitos (Banks, 1992). 
A função excretora do fígado está direcionada a síntese e secreção de substâncias que são lançadas na bile, esta que é secretada pelos hepatócitos e excretada através do sistema de ductos biliares, capaz de alterar a composição da bile, desempenhando papel importante na digestão de gorduras (Cunningan, 2008).

O presente estudo tem como objetivo avaliar os fatores epidemiológicos como (porte, raça, peso corpóreo, peso do fígado, sexo e idade) do fígado de cães necropsiados pelo serviço de anatomia patológica animal do Hospital Veterinário da UNOESTE - Universidade do Oeste Paulista.

\section{REVISÃO BIBLIOGRAFICA}

As lesões que acometem o fígado são de origem degenerativa, inflamatória (tóxica e infecciosa) e neoplásicas. O processo inflamatório que acomete o fígado é denominado hepatite, podendo esta ser de origem tóxica, onde a reação celular inflamatória pode ser mínima, ou de origem infecciosa, tendo como agentes as bactérias, protozoários e os vírus (Jones et al, 2000).

Entre as doenças de origem viral que acomete os cães, a hepatite infecciosa canina é a mais comum. (Thomson, 1998). Dentre os agentes bacterianos que causam hepatite a Leptospira spp e a Salmonela spp são os mais frequentes, enquanto que, a Leishmania spp e o toxoplasma gondi são os protozoários responsáveis pelas hepatites em cães (Jones et al, 2000).

Insultos infecciosos e degenerativos que afetam o fígado, provocando reações inflamatórias de vários padrões, onde o termo hepatite se aplica (JUBB et al, 2007). Sendo esta a inflamação do parênquima do fígado, necrose hepatocelular e apoptose (Mc GAVIN et al,2007).

O termo de hepatite crônica é designado para doença de necroinflamação crônica que tenha durado mais de 6 meses, modificado através da especificação da etiologia, tipo e gravidade da inflamação e do grau de distribuição da necrose. Ela pode se desenvolver após a obstrução biliar crônica, pode ser de origem toxica, induzido por drogas, ou possivelmente auto-imune (JUBB et al, 2007).

A Cirrose é um processo patológico caracterizado como fase terminal da doença hepática, com distorção arquitetural, alterações circulatórias e metabólicas, podendo ou não apresentar atividade inflamatória, definindo-se como cirrose ativa (presença de atividade inflamatória) ou inativa (ausência de atividade inflamatória) (Tostes, 2003). 
Se tratando das neoplasias, elas podem surgir a partir dos hepatócitos, epitélio dos ductos biliares, e endotélio, já que o fígado é um órgão de frequente metástase neoplásica. Como ocorre na maioria delas, sua causa é desconhecida (Jones et al, 2000).

\section{MATERIAL E MÉTODO}

\section{Local da Colheita das Amostras}

As amostras foram colhidas de fígados de cães necropsiados da rotina do serviço de patologia animal do Hospital Veterinário, no serviço de anatomia patológica no Hospital Veterinário da UNOESTE - Universidade do Oeste Paulista, município de Presidente Prudente- São Paulo. O trabalho faz parte de um projeto registrado na CEUA com o № 1188.

\section{Período e Número Amostral}

Foram colhidas 41 amostras de fígado de cães necropsiados com idade, sexo, raça e portes variados; no período de julho de 2012 a maio de 2013.

\section{Colheita das amostras}

Os fígados foram colhidos e pesados, na rotina do serviço de anatomia patologia do Hospital Veterinário da UNOESTE - Universidade do Oeste Paulista, município de Presidente Prudente- São Paulo.

\section{Avaliação das amostras}

Todos os fígados foram mensurados quanto ao seu peso, peso do animal, padrão racial, sexo e idade dos animais. Quanto ao porte, os animais foram classificados conforme a descrição da Royal Canin ${ }^{\circledR}$.

\section{Análise estatística}

Foi realizada uma análise descritiva quanto às porcentagens de animais em seus variados portes, sexo, idade, raças, e comparativo de fígado em relação ao peso corpóreo.

\section{RESULTADOS}

\section{Estatística descritiva epidemiológica dos animais}

\section{Quanto ao sexo:}

Entre os animais estudados, as fêmeas apresentaram-se em maior quantidade, representando $68 \%$ (28 animais) e os machos $32 \%$ (13 animais). 


\section{SEXO}

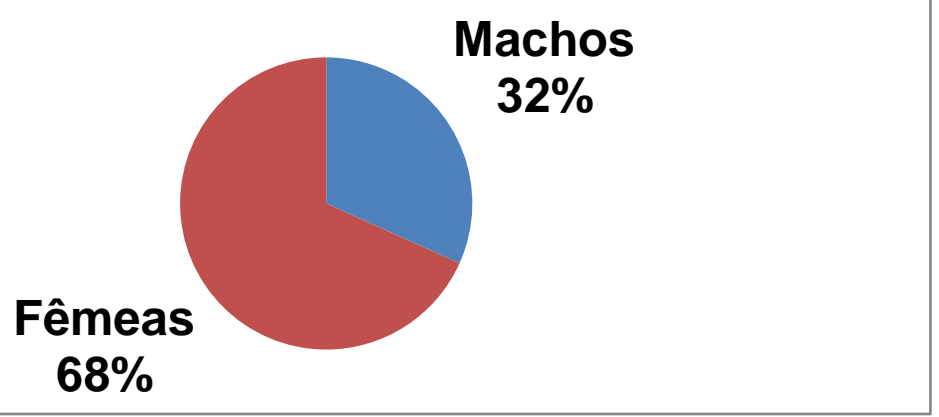

Figura 1. Sexo dos 41 cães estudados

\section{Porte dos animais:}

Segundo o gráfico constatamos que $46 \%$ dos animais foram de Pequeno porte (19 animais), em seguida os animais de porte Médio representaram 39\% (16 animais), e em menor quantidade os animais de porte Max, com 15\% (6 animais), e nenhum animal de porte gigante foi estudado.

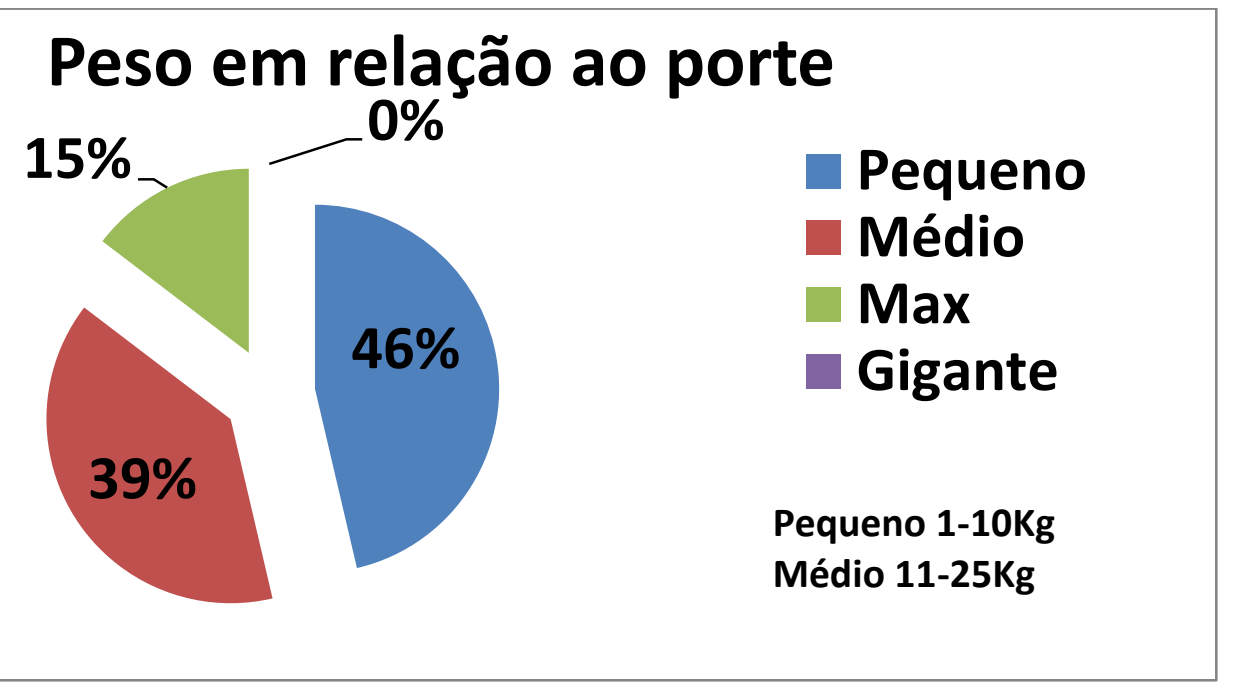

Figura 2. Distribuição do porte dos 41 cães estudados

\section{Padrão racial:}

Dos 41 cães estudados, a raça de maior frequência foi animais sem raça definida (SRD), com 63\% (26 animais), em seguida a raça Poodle com 11\% (4 animais), os Pit Bull representando 8\% (3 animais), Border Collie com 6\% (2 animais), e o restante, sendo eles das raças, Boxer, Chow Chow, Dalmata, Tekel, Rottweiler e Blue Ridler todos com 2\% cada (1 animal). 


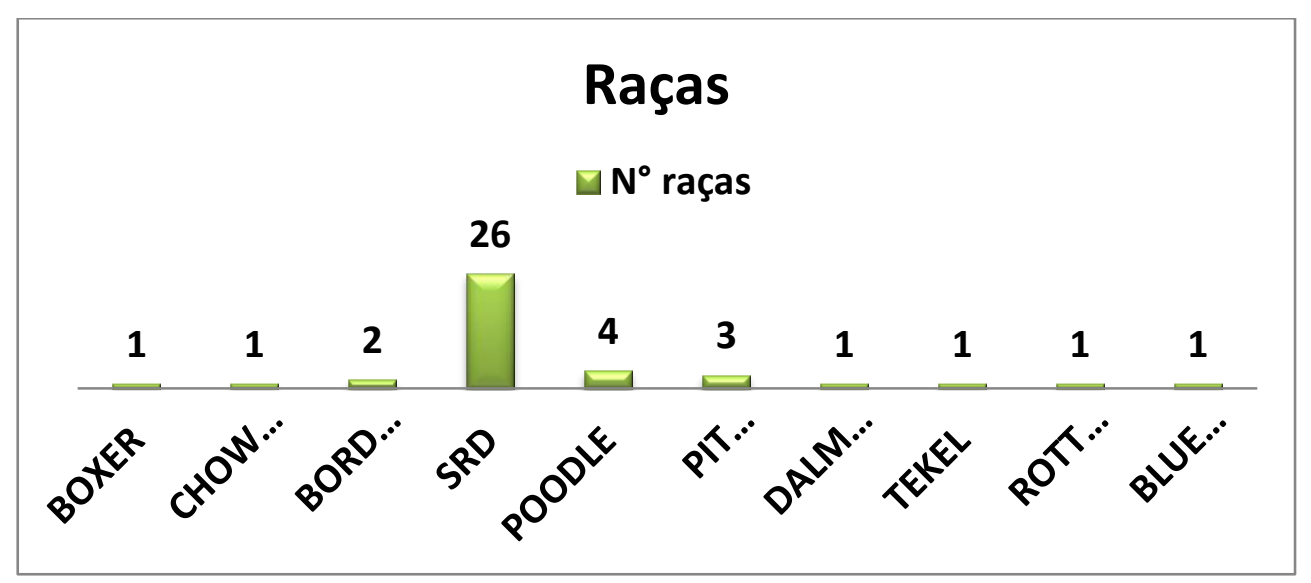

Figura 3. Distribuição racial dos 41 cães estudados

\section{Idade dos animais:}

A idade dos animais variou de 4 meses a 12 anos, onde os animais Jovens representaram 19,5\% (8 animais), os Adultos jovens 12,2\% (5 animais), Adultos 53,7\% (22 animais) e os cães Idosos representaram 14,6\%(6 animais).

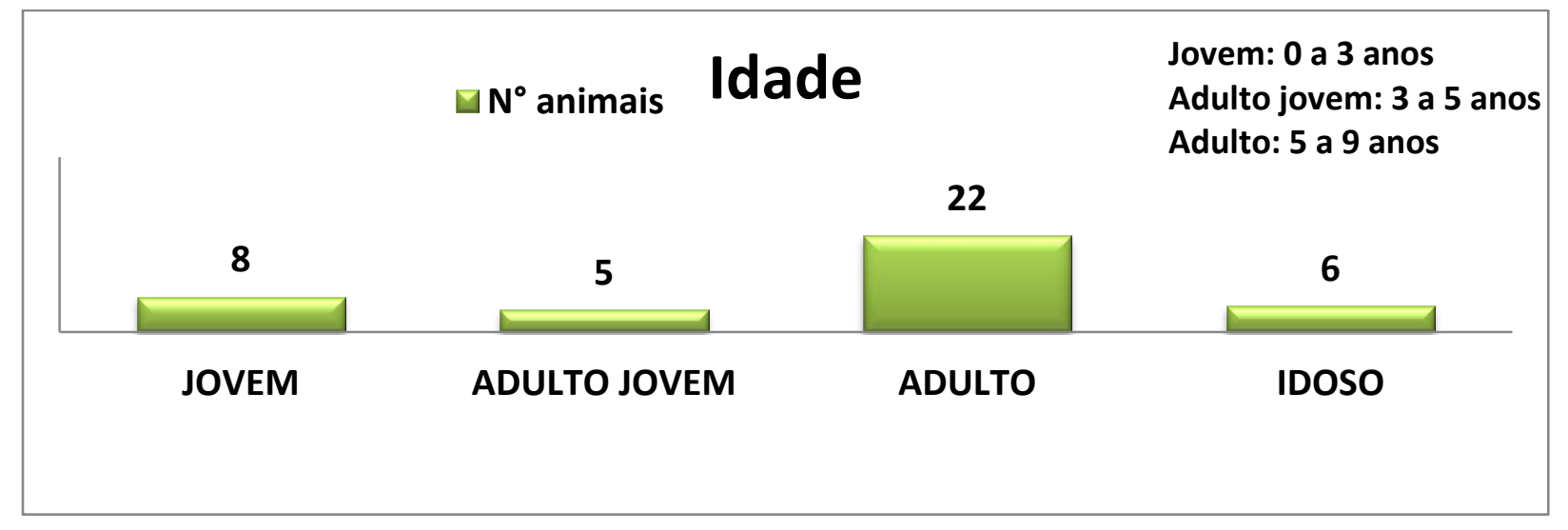

Figura 4. Idade dos cães estudados

Fígados em relação ao peso corpóreo:

Em relação ao peso vivo do animal a média representativa de todos os fígados foi de 4,47\%, corroborando com os dados de Banks (1992) e Dyce et al (1990). Entretanto, 10\% (4 animais) dos fígados apresentaram peso abaixo dos $2 \%$ do peso corpóreo, 61\% (25 animais) possuíam fígado entre 2 a 5\%, e 29\% dos animais (12 animais) o fígado estava acima dos 5\% do peso corpóreo, como mostra a figura 5. 


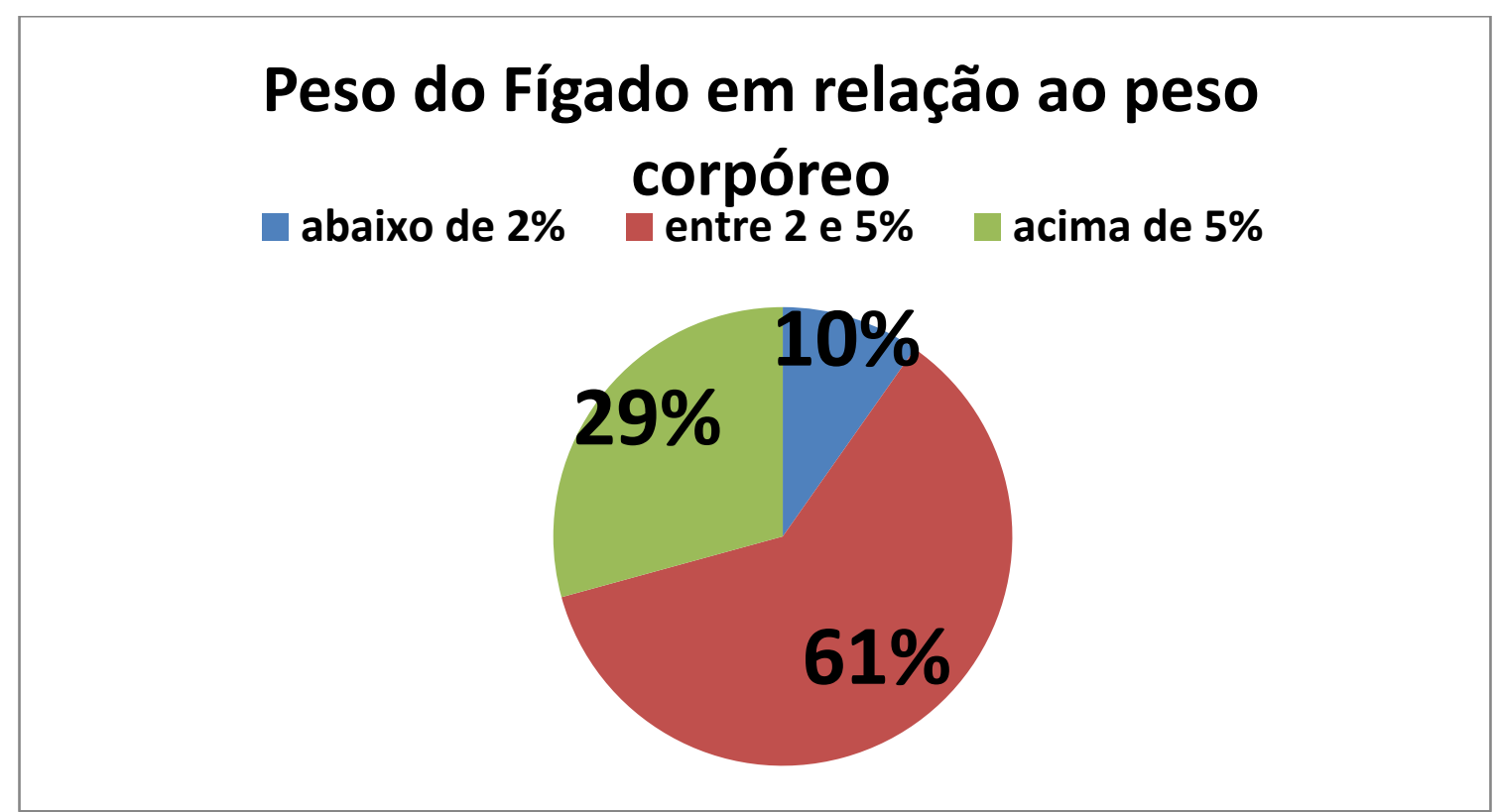

Figura 5. Relação do peso do fígado em relação ao peso vivo do animal

\section{DISCUSSÃO}

O presente estudo mostra que as fêmeas foram mais acometidas, representando $69 \%$ dos animais estudados, quanto ao padrão racial os animais sem raça definida (SRD) apresentaram 63\%, Poodle 11\%, Pit Bull 8\%, Border Collie 6\%, sendo Boxer, Chow Chow, Dalmata, Tekel, Rottweiler e Blue Ridler, representados por 2\% cada, apesar da literatura não indicar prevalência sexual e racial para as doenças hepáticas.

Quanto ao porte animais, os cães de Pequeno porte representaram 46\% (19 animais), os de porte médio 39\% (16 animais), já os de porte Max com 15\% (6 animais), e nenhum animal de porte gigante foi estudado. Já a idade variou de 4 meses a 12 anos, onde os Jovens representaram 19,5\% (8 animais), os adultos jovens 12,2\% (5 animais), adultos 53,7\% (22 animais) e os cães idosos 14,6\%(6 animais), confirmando os dados encontrados em outros estudos, que afirmam que doença hepática acomete cães adultos a velhos.

A média de peso dos fígados estudados em relação ao peso vivo foi de $4,47 \%$, corroborando com os dados da literatura, que indica a média normal de 2 a 5\%. Contudo, 10\% (4 animais) dos fígados apresentaram abaixo dos 2\% do peso corpóreo, 61\% (25 animais) possuíam fígado entre 2 a 5\%, e $29 \%$ dos animais (12 animais) o fígado estava acima dos 5\% do peso corpóreo. 


\section{REFERÊNCIAS}

BANKS, W. J.; D.V.M., MS., Ph.D., Sistema Digestivo II - Orgãos Extra Murais. In: Histologia Veterinária Aplicada. 2ª ed. São Paulo, p. 468-478, 1992.

CUNNINGHAM, J. G., D.V.M PhD; KLEIN, B. G., PhD., Secreções do trato gastro intestinal. In: Tratado de Fisiologia Veterinária. ELSevier, 4.ed., Rio de Janeiro, Cap. 29, p. 337, 2008.

DYCE, K. M., D.V.M \& S., B. Sc., M. R. C. V. S.; SACK, W. O. D.V.M., Ph.D., Dr. med. vet.; WENSING, C. J. G., D.V.M., Ph.D.,O Abdome dos Carnívoros. In: Tratado de Anatomia Veterinária. Guanabara Koogan: Rio de Janeiro, Cap. 14, p. 290-291, 1990.

JONES, T. C., HUNT, R. D., KING, N. W. Sistema Digestivo. In: Patologia Veterinária. São Paulo, 6.ed., Cap. 23, p. 1116-1124, 2000.

MARGARET, J., STALKER AND M. A. (TONY) HAYES. Liver and biliary system. In: Maxie, M. GRANT. JUBB, KENNEDY, AND PALMER'S - Pathology of Domestic Animals. Saunders Elsevier: Philadelphia, v. 2, 5.ed., 2007.

MCGAVIN, M. D., CARLTON, W. W. In: Patologia veterinária especial de Thomson. Artmed: Porto Alegre, 2.ed., 1998.

MCGAVIN, M. D., JAMES, F. Z.; Liver, Biliary system, and Exocrine pancreas. In: Pathologic basis of veterinary disease. Morby Elsevier: St. Louis, Missouri, 4.ed., Cap. 8, 2007.

TOSTES, R. A., Avaliação Histológica da Fibrose na doença hepática crônica canina: Analise semiquantitativa por escores, analise digital morfometrica e detecção imunohistoquimica de adeno vírus canino tipo 1(CAV 1). Tese de Doutorado. 2003. Universidade Estadual Julio de Mesquita Filho. Botucatu, São Paulo. 19f.

http://www.royalcanin.com.br/newsletter/cao-filhote/seu-cao-adulto-de-porte-mini. Acessado em 26 de agosto de 2013. 